\title{
Comparison of Bone Marrow-derived Mononuclear Cells vs. Mesenchymal Stem Cells in Protecting Random-pattern Skin Flap Survival in Rats
}

Peng Xu, Yang Lu, Zhenxing Wang, Jie Lian, Guangdong Zhou, Wei Liu, Yilin Cao, Wei Li* and Wen Jie Zhang*

Department of Plastic and Reconstructive Surgery, National Tissue Engineering Center of China, Shanghai 200011, China

\begin{abstract}
Both cultured Bone Marrow Mesenchymal Stem Cells (BMSCs) and non-cultured Bone Marrow Mononuclear Cells (BM-MNCs) can improve random-pattern skin flap survival. However, whether prior culture expansion of bone marrow cells is beneficial for this therapy remains unclear. In the current study, the protective effects of BM-MNCs and BMSCs derived from identical bone marrow aspirates were compared in a random-pattern skin flap rat model. The mean skin flap survival rates were $71.6 \pm 8.4 \%$ in the BM-MNC-treated group and $66.2 \pm 3.1 \%$ in the BMSCtreated group, both of which were significantly higher than the control group $(55.9 \pm 3.4 \%)$. The protective effects were confirmed by blood perfusion analysis and vessel density assay. However, no significant difference was observed between the cell transplanted groups. These results indicate that the current method for pre-culture of BMSCs does not bring therapeutic benefits in skin flap protection. Therefore, BM-MNCs without pre-culture might be more practicable in the clinical setting.
\end{abstract}

Keywords: Random-pattern skin flap; Cell therapy; Bone marrow mononuclear cells; Bone marrow mesenchymal stem cells

\section{Introduction}

The random-pattern skin flap is one of the most widely used flaps in the repair of skin defects. However, partial necrosis, especially in the distal part, is a major problem because of lack of blood supply and severe ischemia [1]. This problem therefore limits the length-width ratio of random-pattern skin flaps. Previous researchers have found that sympatholytic drugs, vasodilators and calcium channel blockers, could improve ischemia of skin flaps [2,3]. However, applying high doses of these drugs can lead to many side-effects. Various growth factors, including vascular endothelial growth factor (VEGF), basic fibroblast growth factor (b-FGF) and transforming growth factor- $\beta$ (TGF- $\beta$ ), have been proven to be beneficial for the survival of skin flaps, although they are also restricted by their short half-life and poor longlasting effects [4-6].

In recent years, cell therapy has become a new strategy for tissue repair and regeneration. Both Bone Marrow Mononuclear CElls (BM-MNCs) and Bone Marrow Mesenchymal Stem Cells (BMSCs) derived from bone marrow cell culture have been proven to improve skin flap survival $[7,8]$. However, it is unclear which cell population is optimal for treatment. Ideally, if a small number of BM-MNCs could be expanded to achieve a large number of BMSCs without losing their protective function, the amount of bone marrow aspirate could be greatly reduced to meet current clinical requirements. On the contrary, if cells lost their protective function during cultivation, cell expansion might not be favorable for clinical application. To date, no study has compared the protective potential of cultured and non-cultured bone marrow cells in skin flap survival. To address this, we measured the phenotypic changes of bone marrow cells before and after culture, and compared the protective effects of non-cultured BM-MNCs and expanded BMSCs derived from the same bone marrow aspirates in a random-pattern skin flap rat model.

\section{Materials and Methods}

Male Wistar rats (3-6 weeks old) were purchased from Shanghai Chuansha Experimental Animal Raising Farm (Shanghai, China). Animal procedures were approved by The Animal Care and Experiment
Committee of Shanghai Jiao Tong University School of Medicine. All animals were maintained in a pathogen-free environment. Surgical procedures were performed under aseptic conditions.

\section{Isolation of BM-MNCs}

Isolation of BM-MNCs was performed according to standard protocol [8]. Briefly, male Wistar rats (3 weeks old) were sacrificed by cervical dislocation. Bilateral femurs and tibias were dissected and the bone marrow was harvested and suspended in low glucose Dulbecco's Modified Eagle Medium (DMEM; Invitrogen, Carlsbad, CA, USA) with $10 \%$ fetal bovine serum (FBS; HyClone, Logan, UT, USA). BMMNCs were isolated by density gradient centrifugation of bone marrow cells on Ficoll-paque (Sigma, St. Louis, MO). Cells were resuspended in phosphate buffered saline (PBS) before transplantation.

\section{Expansion of BMSCs}

Bone marrow was harvested and cultured to expand BMSCs as previously described [9]. Briefly, whole bone marrow cells were plated onto tissue culture dishes in DMEM with 10\% FBS and maintained at $37^{\circ} \mathrm{C}$ in $5 \% \mathrm{CO} 2$. After 24 hours, the plates were washed with PBS to remove non-adherent cells. The resulting adherent cells were grown

*Corresponding authors: Wei $\mathrm{Li}$, Department of Plastic and Reconstructive Surgery, Shanghai 9th People's Hospital, Shanghai Jiao Tong University School of Medicine, Shanghai Key Laboratory of Tissue Engineering, National Tissue Engineering Center of China, Shanghai 200011, China, Tel: +86-21-23271699; Fax: +86-21-53078128; E-mail: liweiboshi@163.com

Wen Jie Zhang, Department of Plastic and Reconstructive Surgery, Shanghai 9th People's Hospital, Shanghai Jiao Tong University School of Medicine, Shangha Key Laboratory of Tissue Engineering, National Tissue Engineering Center of China, Shanghai 200011, China, Tel: +86-21-23271699; Fax: +86-21-53078128; E-mail: wenjieboshi@aliyun.com

Received July 09, 2016; Accepted August 16, 2016; Published August 22, 2016

Citation: Xu P, Lu Y, Wang Z, Lian J, Zhou G, et al. (2016) Comparison of Bone Marrow-derived Mononuclear Cells vs. Mesenchymal Stem Cells in Protecting Random-pattern Skin Flap Survival in Rats. J Stem Cell Res Ther 6: 355. doi: 10.4172/2157-7633.1000355

Copyright: ( 2016 Xu P, et al. This is an open-access article distributed under the terms of the Creative Commons Attribution License, which permits unrestricted use, distribution, and reproduction in any medium, provided the original author and source are credited. 
to confluence within 7 days. Cells were subcultured every 4 days using $0.25 \%$ trypsin/EDTA (Sigma) and collected for transplantation at passage $4\left(\mathrm{P}_{4}\right)$.

\section{Multilineage differentiation of BMSCs}

The adipogenic, osteogenic and chondrogenic differentiation of BMSCs (passage 4) were performed respectively as previously described $[10,11]$. After 3 weeks of induction, adipogenic differentiation was measured by Oil red $\mathrm{O}$ staining; osteogenic differentiation was detected by Alizarin red staining; and chondrogenic differentiation was measured by Alcian blue staining. All the stainings were performed according to the standard protocols $[10,11]$.

\section{Flow cytometric analysis of BM-MNCs and BMSCs}

Freshly isolated BM-MNCs or cultured BMSCs $\left(\mathrm{P}_{4}\right)$ were collected and $5 \times 10^{5}$ cells were resuspended in $200 \mu \mathrm{l}$ of wash buffer (PBS containing 4\% FBS). Freshly diluted fluorescein isothiocyanate (FITC)conjugated anti-CD29 (1:200), CD90, phycoerythrin (PE)-conjugated anti-CD45 (all from BD Pharmingen, San Diego, CA), CD14, CD133, CD144, KDR, CD31 and CD34 (all from Santa Cruz Biotechnology Inc; Santa Cruz, CA ) monoclonal antibodies were added individually into respective tubes and incubated on ice for 30 minutes. After three washes, cells were resuspended in wash buffer for analysis. FITC or PE conjugated isotype-matched immunoglobulins were used to determine nonspecific staining. Cells were analyzed on a FACS Caliber (BectonDickinson, San Jose, CA) and data were analyzed with Cell Quest software (Becton-Dickinson).

\section{Skin flap model and cell transplantation}

The skin flap model and cell transplantation procedure are shown in Figure 1. In brief, 6-week-old Wistar rats were anesthetized with chloral hydrate $(0.4 \mathrm{~mL} / 100 \mathrm{~g})$ and the dorsal skins were shaved using electric clippers. Two days before operation (day -2), cells were subcutaneously injected in 7 points on the dorsal skin evenly (cell numbers for transplantation are described below). On day 0 , an $8-\mathrm{cm} \times 2-\mathrm{cm}$ random-pattern skin flap was raised and sutured back in situ using a 3-0 silk suture [12]. The survival area of the skin flaps was measured on day 7 .

To identify an optimal cell dose for therapy, either $1 \times 10^{6}$ or $5 \times 10^{6}$ of freshly isolated BM-MNCs were injected into rats ( $n=6 /$ group). The same volume of PBS was injected as a control $(n=6)$. The survival of the skin flaps was measured on day 7 and an optimal cell dose of $5 \times 10^{6}$ cells per rat was chosen for further experimentation.
To compare the therapeutic effects of BM-MNCs and BMSCs, bone marrow aspirates collected from 4 rats were divided equally into halves. One half was used to isolate BM-MNCs directly and the other half was used to expand BMSCs in culture as described above. Step 1: the total cell number of BM-MNCs was counted and the total number of animals that could be treated with the BM-MNCs was calculated by (total BM-MNC number) $/\left(5 \times 10^{6}\right)$. Step 2 : the total cell number of BMSCs at passage 4 was counted and an equivalent number of cells to be injected into each animal was calculated by (total BMSC number)/ (total numberof animals that could be treated by BM-MNCs). Step 3: $5 \times 10^{6}$ of BM-MNCs or equivalent number of BMSCs were suspended in $700 \mu \mathrm{l}$ of PBS and subcutaneously injected in each animal (7 injection points in each animal with $100 \mu \mathrm{l}$ in each point, $\mathrm{n}=6$ /group). Control animals received the same volume of PBS $(n=6)$.

\section{Survival of skin flaps}

On day 7, rats were anesthetized and images of each flap were taken with a digital camera. The survival area of each flap was grossly determined based on its appearance, color and texture. The survival area was quantified by Image-Pro Plus software (Version 6.0, Media Cybernetics, Rockville, MD). Results were expressed as percentage of survival in relation to the total surface area of the skin flap.

\section{Blood perfusion measurement}

On day 7, rats were anesthetized and blood perfusions of the skin flaps were detected with a Full-Field Laser Perfusion Imager (FLPI, Moor Instruments Ltd, Axminster, UK). Results were presented as the laser intensity of the flaps.

\section{Histology}

Rats were sacrificed with an overdose of anesthesia on day 7. Specimens were taken from the middle part of each flap. The specimens were fixed in $4 \%$ paraformaldehyde, embedded in paraffin and sectioned as $6-\mu \mathrm{m}$ slices. Immunohistochemical staining of anti-CD31 antibody (Dako, Glostrup, Denmark) was carried out using standard protocol, followed by horseradish peroxidase-conjugated goat antimouse antibody (Dako) and colorized with diaminobenzidine tetrahydrochloride (DAB, Dako). Five randomly selected fields were captured by a light microscope. The number of blood vessels was calculated by Image-Pro Plus software (Version 6.0, Media Cybernetics). Three slices from each group were analyzed.

\section{Statistical analysis}

All data were expressed as mean \pm SD. Comparisons of flap survival
A

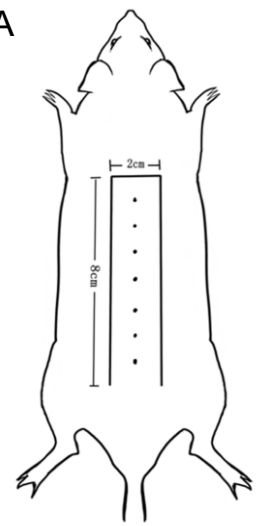

B

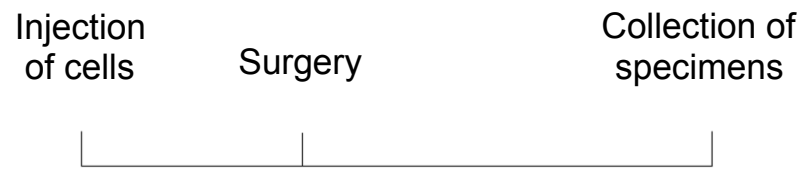

day $-2 \quad$ day $0 \quad$ day 7

Figure 1: A: Schematic chart of the skin flap model. B: The procedure of cell transplantation, surgery and collection of specimens. 
rate and capillary number between groups were performed using the Student-Newman-Keuls $\mathrm{q}$ test. A value of $\mathrm{P}<0.05$ was considered significant.

\section{Results}

\section{Characterization of BM-MNCs and BMSCs}

BMSCs $\left(\mathrm{P}_{4}\right)$ exhibited a typical fibroblast-like morphology with strong proliferation ability in vitro (Figure $2 \mathrm{~A}$ ). These cells were able to differentiate into adipocytes, osteoblasts and chondrocytes in the presence of certain factors (Figures 2B-2D). The cell surface marker expression profiles of BMSCs and non-cultured BM-MNCs were analyzed by flow cytometry. Compared to BM-MNCs, BMSCs expressed higher levels of mesenchymal cell markers CD29 and CD90, but lower levels of endothelial cell marker CD31 and hematopoietic cell marker CD45 (Figure 3).

\section{Optimal cell dose for transplantation}

To determine the optimal cell dose for therapy, $1 \times 10^{6}$ or $5 \times 10^{6}$ of freshly isolated BM-MNCs were injected into rats. On day 7 , the boundaries between survival and necrotic areas were observed in each skin flap (Figure 4A). The mean survival rates of skin flaps were $64.0 \pm$ $6.1 \%$ in the $1 \times 10^{6}$ cell-treated group and $70.8 \pm 5.3 \%$ in the $5 \times 10^{6}$ celltreated group, which were significantly higher than in the PBS group $(54.3 \pm 2.5 \%, \mathrm{P}<0.05)$. However, no significant difference was observed between the cell transplanted groups ( $P>0.05$; Figure $4 \mathrm{~B})$. An optimal dose of $5 \times 10^{6}$ cells per rat was chosen for subsequent experiments.

\section{Flap survival improved by transplantation of BM-MNCs and BMSCs}

Gross views of skin flaps on day 7 of treatment are shown in Figure 5A. Quantitative analyses of skin flap survival rate showed that 66.2 $\pm 3.1 \%$ of flaps survived in the BMSC-treated group and $71.6 \pm 8.4 \%$ in the BM-MNC-treated group, and both groups were significantly higher than the PBS group $(55.9 \pm 3.4 \%, \mathrm{P}<0.05)$. However, no significant difference was observed between the cell transplanted groups $(\mathrm{P}>0.05)$ (Figure $5 \mathrm{~B})$. FFLPI revealed that blood perfusions in the cell transplanted groups were better than those in the PBS group (Figure 5C)

\section{Capillary density in flaps}

To measure capillary density after cell transplantation, immunohistochemical staining of CD31 was performed in the skin flaps collected from identical anatomical positions. As shown in Figure 6 , capillary numbers were $42.7 \pm 5.1$ in the BMSC-treated group and $58.2 \pm 6.8$ in the BM-MNC-treated group, which were significantly higher than the $\mathrm{PBS}$ group $(22.8 \pm 3.1, \mathrm{P}<0.05)$. In addition, a significant difference was observed between the BMSC-treated and BM-MNCtreated groups $(\mathrm{P}<0.05)$.

\section{Discussion}

The pro-angiogenic potentials of BM-MNCs and BMSCs have been demonstrated not only in skin flap survival model but also in the other ischemic diseases [7,8,13-17]. However, which is the optimal cell source for clinical application is not clear. The expansion of cells in culture could reduce the initial amount of bone marrow aspirates, but would limit the treatment in the facilities with qualified cell culture unit and raise the safety concerns about cells after long-term culture. It is important to clarify whether cell expansion could bring great benefit to the therapy.
In order to obtain a certain amount of cells for transplantation, we expanded BMSCs for 4 passages in culture. The multipotency of expanded BMSCs was proved by their adipogenic, osteogenic and chondrogenic differentiation capacity (Figure 2). In addition, flow cytomertic analysis confirmed that cells expressed typical MSC surface markers (Figure 3), indicating that these are functional BMSCs. Our preliminary study found that flap raising could induce tissue inflammatory reaction which may not be good for the survival of transplanted cells. Therefore, we adopt the strategy from Yang et al. that BMSCs and BM-MNCs were injected two days pre-operation [8]. We demonstrated that both freshly isolated BM-MNCs and cultured BMSCs $\left(\mathrm{P}_{4}\right)$ were able to improve random-pattern skin flap survival in a rat model. More importantly, injection of equivalent numbers of BM-MNCs and BMSCs, derived from identical bone marrow aspirates, displayed comparable effects without significant difference, indicating that current cell expansion procedures may not bring therapeutic benefit.

It is well known that neovascularization is crucial for the survival of skin flaps following ischemic injury. However, flap survival may not completely rely on blood supply in such an acute ischemic model. Other protective factors may also play a role in the flap survival. We found that capillary density was significantly higher in BM-MNCs group than that in BMSCs group (Figure 6). This accords with others finding that
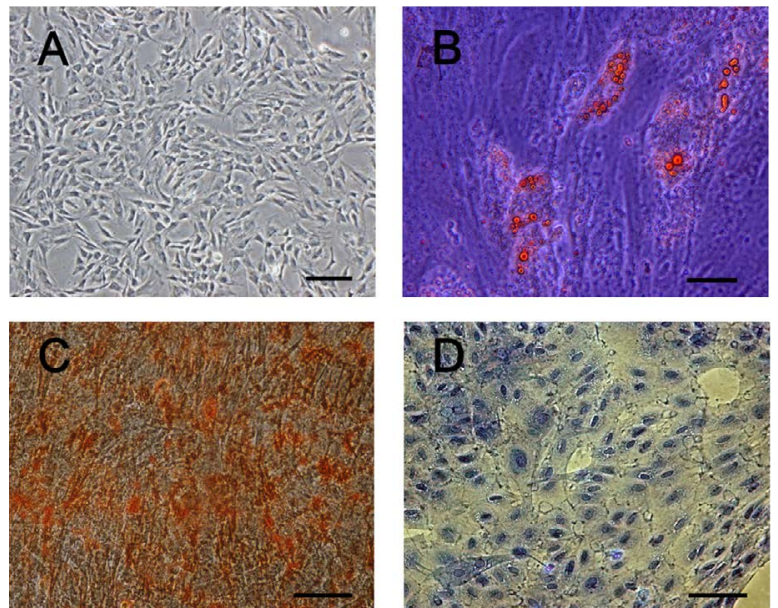

Figure 2: Multipotency of BMSCs at passage 4. A: Fibroblast-like morphology of BMSCs (P4). Scale bar: $200 \mu \mathrm{m}$. B: Oil red O staining of cells after adipogenic induction. Scale bar: $50 \mu \mathrm{m}$. C: Alizarin red staining of cells after osteogenic induction. Scale bar: $100 \mu \mathrm{m}$. D: Alcian blue staining of cells after chondrogenic induction. Scale bar: $100 \mu \mathrm{m}$.

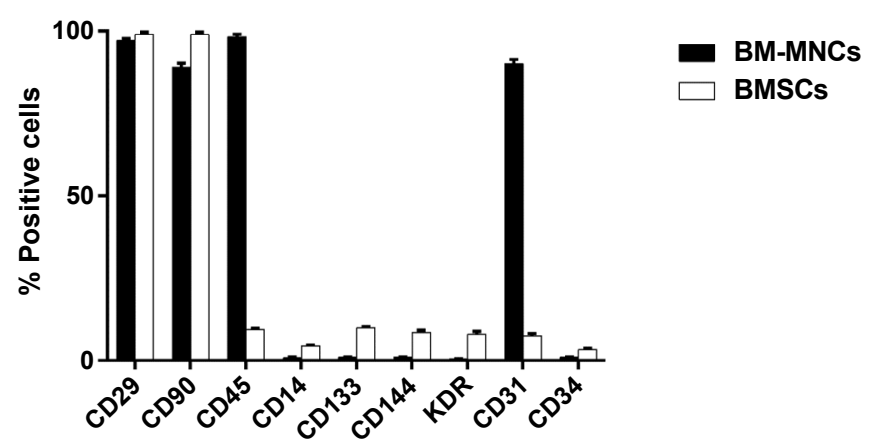

Figure 3: Cell surface marker expression profile of BM-MNCs and BMSCs. 
A

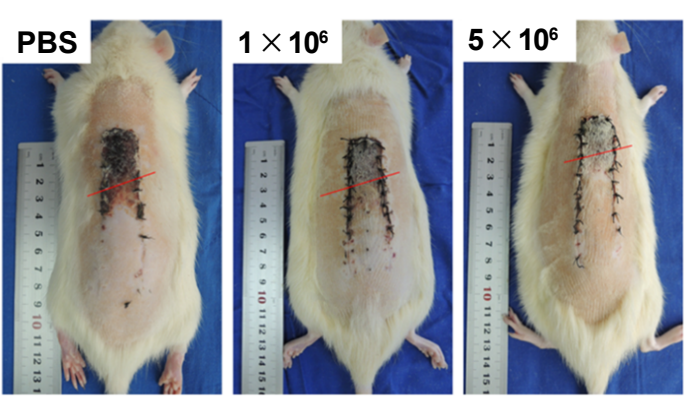

B

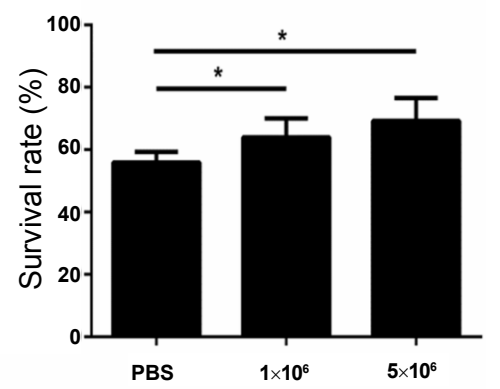

Figure 4: A: Gross view of skin flaps treated by BM-MNCs at day 7. B: Mean survival rate of skin flap in each group $(n=6) .{ }^{*} P<0.05$.


Figure 5: A: Gross view of skin flaps treated by BM-MNCs, BMSCs and PBS at day 7. B: Mean survival rate of skin flaps in each group ( $\mathrm{n}=6$ ). ${ }^{*} \mathrm{P}<0.05 . \mathrm{C}$ : Blood perfusion of skin flaps measured by FLPI.

BM-MNCs could differentiate into endothelial cells to participate in the neovascularization $[8,18]$, while BMSCs barely differentiate into endothelial cells [19-22]. Interestingly, the flap survival rate was similar between BM-MNCs group and BMSCs group (Figure 5). BMSCs have been used in the treatment of many ischemic disorders [23-26]. It has been reported that BMSCs barely participate in neovascularization directly but through paracrine secretion of factors to protect resident cells, promote cell proliferation and neovascularization, and regulate inflammatory responses [19-22]. This may explain why the flap survival rate was similar in both groups. Since cells were not labeled before injection, the exact fate of transplanted cells is not clear. It is worth to be investigated in future.

Although BMSCs area relatively pure population that might be good for reducing cell-related side-effects, other pro-angiogenic components, such as endothelial progenitor cells and hematopoietic cells [27], are lost during expansion (Figure 3). This might be one reason why no further improvement were observed following BMSC treatment compared with BM-MNC treatment. Yang et al. demonstrated that bFGF and VEGF were highly expressed in the flaps receiving $\mathrm{BM}-\mathrm{MNC}$ transplantation [8]. In addition, they proved that the pro-angiogenic effect of BM-MNCs was comparable with adipose derive stem cells (ADSCs), which have been also used to enhance flap survive [28]. Compare to BMSCs and ADSCs, BM-MNCs apparently have distinct advantages that could be used without complicate and time-consuming culture process.

To achieve large amount of functional cells in culture, maintaining the "stemness" of cells during expansion is still a big challenge. The current standard protocol for BMSC culture is widely used but not ideal $[27,29]$. Cells are reported to lose their multipotent differentiation potential in later passages [27]. Cells at P4, which still possessed multipotent differentiation potential (Figure 2), were used for transplantation in this study. Compared with similar studies, the number of cells injected in this study was higher than others [8,30-33]. Despite this, cells expanded at passage 6 could increase the number of cells for injection, but did not improve the protective effects in skin flap survival (data not shown). Clearly, the current culture protocol 

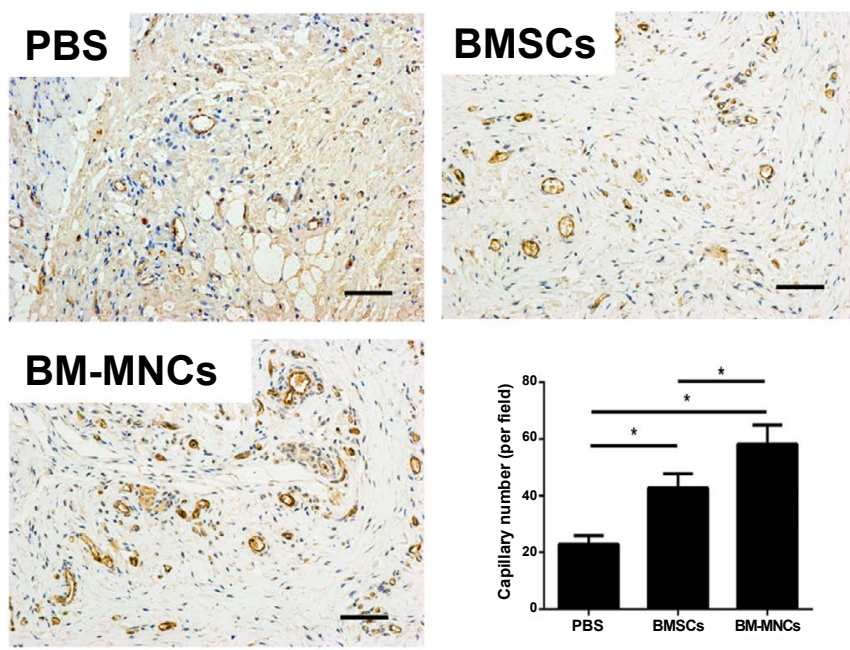

Figure 6: Capillary density in skin flaps measured by immunohistological staining of CD $31 .^{*} \mathrm{P}<0.05$. Scale bars: $100 \mu \mathrm{m}$.

is not suitable for expansion of bone marrow cells for this particular therapeutic purpose. An enhanced cell culture system needs to be developed to meet this requirement.

\section{Conclusion}

This study demonstrates that both BM-MNCs and BMSCs are comparable in improving the survival of random-pattern skin flaps. However, non-cultured BM-MNCs would be more practicable for clinical application.

\section{Conflict of Interest}

None of the authors has a financial interest in any of the products, devices, or drugs mentioned in this manuscript.

\section{Acknowledgments}

This work was supported by the Major State Basic Research Development Program of China (2007CB948004, 2011CB964704) and the National Basic Research Program of China (30800231, 31170944).

\section{References}

1. Kerrigan CL, Daniel RK (1982) Critical ischemia time and the failing skin flap. Plast Reconstr Surg 69: 986-989. [PubMed]

2. Finseth F, Adelberg MG (1978) Prevention of skin flap necrosis by a course of treatment with vasodilator drugs. Plast Reconstr Surg 61: 738-743. [PubMed]

3. Waters LM, Pearl RM, Macaulay RM (1989) A comparative analysis of the ability of five classes of pharmacological agents to augment skin flap survival in various models and species: an attempt to standardize skin flap research. Ann Plast Surg 23: 117-122. [PubMed]

4. Khan A, Ashrafpour H, Huang N, Neligan PC, Kontos C, et al. (2004) Acute local subcutaneous VEGF165 injection for augmentation of skin flap viability: efficacy and mechanism. Am J Physiol Regul Integr Comp Physiol 287: R12191229. [PubMed]

5. Ishiguro N, Yabe Y, Shimizu T, Iwata H, Miura T (1994) Basic fibroblast growth factor has a beneficial effect on the viability of random skin flaps in rats. Ann Plast Surg 32: 356-360. [PubMed]

6. Iwasawa M (1993) Accelerated maturation in prefabricated flaps by transforming growth factor-beta: an experimental study in the rabbit. Ann Plast Surg 31: 72 75. [PubMed]

7. Uysal CA, Ogawa R, Lu F, Hyakusoku H, Mizuno H (2010) Effect of mesenchymal stem cells on skin graft to flap prefabrication: an experimental study. Ann Plast Surg 65: 237-244. [PubMed]
8. Yang M, Sheng L, Li H, Weng R, Li QF (2010) Improvement of the skin flap survival with the bone marrow-derived mononuclear cells transplantation in a rat model. Microsurgery 30: 275-281. [PubMed]

9. Mizuguchi T, Hui T, Palm K, Sugiyama N, Mitaka T, et al. (2001) Enhanced proliferation and differentiation of rat hepatocytes cultured with bone marrow stromal cells. J Cell Physiol 189: 106-119. [PubMed]

10. Davies OG, Cooper PR, Shelton RM, Smith AJ, Scheven BA (2015) Isolation of adipose and bone marrow mesenchymal stem cells using CD29 and CD90 modifies their capacity for osteogenic and adipogenic differentiation. J Tissue Eng 6: 2041731415592356. [PubMed]

11. Lotfy A, Salama M, Zahran F, Jones E, Badawy A, et al. (2014) Characterization of mesenchymal stem cells derived from rat bone marrow and adipose tissue: a comparative study. Int J Stem Cells 7: 135-142. [PubMed]

12. Shalom A, Friedman T, Westreich M (2008) Effect of aspirin and heparin on random skin flap survival in rats. Dermatol Surg 34: 785-790. [PubMed]

13. Jiang C, Wang J, Yu L, Ou C, Liu X, et al. (2013) Comparison of the therapeutic effects of bone marrow mononuclear cells and microglia for permanent cerebral ischemia. Behav Brain Res 250: 222-229. [PubMed]

14. Hao CN, Shintani S, Shimizu Y, Kondo K, Ishii M, et al. (2014) Therapeutic Angiogenesis by Autologous Adipose-Derived Regenerative Cells: Comparison With Bone Marrow Mononuclear Cells. Am J Physiol Heart Circ Physiol 307: H869-H879. [PubMed]

15. Mazo M, Gavira JJ, Abizanda G, Moreno C, Ecay M, et al. (2010) Transplantation of mesenchymal stem cells exerts a greater long-term effect than bone marrow mononuclear cells in a chronic myocardial infarction model in rat. Cell Transplant 19: 313-328. [PubMed]

16. Yang Z, Zhu L, Li F, Wang J, Wan H, et al. (2014) Bone marrow stromal cells as a therapeutic treatment for ischemic stroke. Neurosci Bull 30: 524-534. [PubMed]

17. Olivares EL, Ribeiro VP, de Castro JPW, Ribeiro KC, et al. (2004) Bone marrow stromal cells improve cardiac performance in healed infarcted rat hearts. Am J Physiol Heart Circ Physiol 287: H464-H470. [PubMed]

18. Shintani S, Murohara T, Ikeda H, Ueno T, Sasaki K, et al. (2001) Augmentation of postnatal neovascularization with autologous bone marrow transplantation. Circulation 103: 897-903. [PubMed]

19. Gnecchi M, He H, Liang OD, Melo LG, Morello F, et al. (2005) Paracrine action accounts for marked protection of ischemic heart by Akt-modified mesenchymal stem cells. Nat Med 11:367-368. [PubMed]

20. Li Y, Chen J, Chen XG, Wang L, Gautam SC, et al. (2002) Human marrow stromal cell therapy for stroke in rat: neurotrophins and functional recovery. Neurology 59: 514-523. [PubMed]

21. Ortiz LA, Dutreil M, Fattman C, Pandey AC, Torres G, et al. (2007) Interleukin 1 receptor antagonist mediates the antiinflammatory and antifibrotic effect of mesenchymal stem cells during lung injury. Proc Natl Acad Sci U S A 104 11002-11007. [PubMed]

22. Togel F, Hu Z, Weiss K, Isaac J, Lange C, et al. (2005) Administered mesenchymal stem cells protect against ischemic acute renal failure through differentiation-independent mechanisms. Am J Physiol Renal Physiol 289: F31 42. [PubMed]

23. Benzhi C, Limei Z, Ning W, Jiaqi L, Songling Z, et al. (2009) Bone marrow mesenchymal stem cells upregulate transient outward potassium currents in postnatal rat ventricular myocytes. J Mol Cell Cardiol 47: 41-48. [PubMed]

24. Orlic D, Kajstura J, Chimenti S, Bodine DM, Leri A, et al. (2003) Bone marrow stem cells regenerate infarcted myocardium. Pediatr Transplant 7 Suppl 3: 8688. [PubMed]

25. Procházka V, Gumulec J, Chmelová J, Klement P, Klement GL, et al. (2009) Autologous bone marrow stem cell transplantation in patients with end-stage chronical critical limb ischemia and diabetic foot. Vnitr Lek 55: 173-178. [PubMed]

26. Wang L, Lin Z, Shao B, Zhuge Q, Jin K (2013) Therapeutic applications of bone marrow-derived stem cells in ischemic stroke. Neurol Res 35: 470-478. [PubMed]

27. Zhang W, Zhang F, Shi H, Tan R, Han S, et al. (2014) Comparisons of rabbit bone marrow mesenchymal stem cell isolation and culture methods in vitro. PLoS One 9: e88794. [PubMed] 
Citation: Xu P, Lu Y, Wang Z, Lian J, Zhou G, et al. (2016) Comparison of Bone Marrow-derived Mononuclear Cells vs. Mesenchymal Stem Cells in Protecting Random-pattern Skin Flap Survival in Rats. J Stem Cell Res Ther 6: 355. doi: 10.4172/2157-7633.1000355

28. Lu F, Mizuno H, Uysal CA, Cai X, Ogawa R, et al. (2008) Improved viability of random pattern skin flaps through the use of adipose-derived stem cells. Plast Reconstr Surg 121: 50-58. [PubMed]

29. Li X, Zhang Y, Qi G (2013) Evaluation of isolation methods and culture conditions for rat bone marrow mesenchymal stem cells. Cytotechnology 65: 323-334. [PubMed]

30. Li H, Zan T, Li Y, Weng R, Yang M, et al. (2010) Transplantation of adiposederived stem cells promotes formation of prefabricated flap in a rat model. Tohoku J Exp Med 222: 131-140. [PubMed]
31. Reichenberger MA, Heimer S, Schaefer A, Lass U, Gebhard MM, et al. (2012) Adipose derived stem cells protect skin flaps against ischemia-reperfusion injury. Stem Cell Rev 8: 854-862. [PubMed]

32. Karathanasis V, Petrakis S, Topouridou K, Koliakou E, Koliakos G, et al. (2013) Intradermal injection of GFP-producing adipose stromal cells promotes survival of random-pattern skin flaps in rats. Eur J Plast Surg 36: 281-288.

33. Reichenberger MA, Mueller W, Schäfer A, Heimer S, Leimer U, et al. (2012) Fibrin-embedded adipose derived stem cells enhance skin flap survival. Stem Cell Rev 8: 844-853. [PubMed] 